\title{
Effects of Long Distance Transportation on Honey Bee Physiology
}

\author{
Kiheung Ahn, ${ }^{1}$ Xianbing Xie, ${ }^{1,2}$ Joseph Riddle, ${ }^{1}$ Jeff Pettis, ${ }^{3}$ and Zachary Y. Huang ${ }^{1}$ \\ ${ }^{1}$ Department of Entomology, Michigan State University, East Lansing, MI 48824, USA \\ ${ }^{2}$ Department of Laboratory Animal Science, Nanchang University, Nanchang, Jiangxi 330006, China \\ ${ }^{3}$ Bee Research Laboratory, USDA Agricultural Research Service, Beltsville, MD 20705, USA \\ Correspondence should be addressed to Zachary Y. Huang, bees@msu.edu
}

Received 4 April 2012; Accepted 24 May 2012

Academic Editor: Tugrul Giray

Copyright ( 2012 Kiheung Ahn et al. This is an open access article distributed under the Creative Commons Attribution License, which permits unrestricted use, distribution, and reproduction in any medium, provided the original work is properly cited.

Despite the requirement of long distance transportation of honey bees used for pollination, we understand little how transportation affects honey bees. Three trials in three different states (CA, GA, and MI) were conducted to study the effects of long distance transportation on honey bee physiology. Newly emerged bees from one colony were split into two groups and introduced into a transported $(\mathrm{T})$ colony or a stationary $(\mathrm{S})$ colony in each trial. Volumes of hypopharyngeal gland acini in $\mathrm{T}$ colonies were significantly smaller than $\mathrm{S}$ colonies in all three trials. There were no significant differences between $\mathrm{S}$ and $\mathrm{T}$ colonies in juvenile hormone titers. Protein content in head showed no significant differences between $\mathrm{S}$ and $\mathrm{T}$ either in 7 day-old or 17-day-old bees of MI trial, but GA trial showed a significant reduction in bees experiencing transportation. Protein content in thorax was only measured in GA trial and was not significantly different between the two groups. Lipid content in abdomen was not significantly different between the $S$ and $T$ colonies in all three trials. This study suggests that bees experiencing transportation have trouble fully developing their food glands and this might affect their ability to nurse the next generation of workers.

\section{Introduction}

Honey bees (Apis mellifera) are perhaps the most important insects to humans due to their pollination service provided to agriculture [1]. Honey bees experience many different types of stresses. They are impacted by parasitic mites such as Varroa destructor and Acarapis woodi [2], microsporidian pathogens such as Nosema apis and Nosema ceranae [3], hundreds of pesticides applied in crops and brought back by foragers [4], as well as pesticides beekeepers applied inside the colonies [5]. Besides these stresses, perhaps the strongest stress experienced by honey bees is long distance transportation. For example, bees are transported from Florida to California, across four time zones in the spring for almond pollination. About $50 \%$ of bee colonies in Michigan also migrate to south (e.g., Georgia and Florida) for overwintering and then are moved back for apple and cherry pollination. Yet we understand little of the effects of the long distance transportation on bees because no studies have ever been conducted to determine the physiological or behavioral changes induced by such stress.
Honey bees have an age-related division of labor whereby young workers stay inside taking care of brood (nurses), and old bees forage for food (nectar and pollen) and other resources (water and propolis). This progression of behavioral changes is associated with juvenile hormone (JH), with nurses having low levels of $\mathrm{JH}$ and foragers having high ones [6-8]. Although $\mathrm{JH}$ is not considered a stress hormone [9], JH titers in blood can tell us whether workers are switching to become foragers or not. JH has been shown to be antagonistic to vitellogenin ( $\mathrm{Vg}$ ) [10], whereby bees with low $\mathrm{JH}$ always have high $\mathrm{Vg}$ and high $\mathrm{JH}$ suppresses $\mathrm{Vg}$. $\mathrm{Vg}$ has been shown to be associated with slower aging because it protects workers from oxidative stress [11, 12] and is higher in queens [13], who live longer than workers. Workers that are ready to forage are characterized with high $\mathrm{JH}$, low $\mathrm{Vg}$, low abdomen fat, and lower body protein, essentially becoming "disposable" from the colony's point of view. JH therefore is a reliable indicator of the physiological age of workers. The hypopharyngeal glands (HPGs) of honey bees play a critical role in social 
cohesion, because they provide secretions rich in protein, which are fed to larvae of all three castes, and also to adult queen, drones $[14,15]$, and foragers [16]. The sizes of HPG reflect how good a protein nutrition the bees have obtained prior to becoming nurses and may affect their nursing ability $[17,18]$ or it can reflect the effect of pathogens such as Nosema apis [19]. The amount of abdomen fat is another indicator for when workers become foragers, with nurses having high levels and foragers low levels [20]. Protein levels in workers will tell us whether workers during transportation can still obtain adequate protein nutrition or not. For example, can they still find/eat the same amount of pollen while "on the move" on the truck? Are their digestion efficiency affected by transportation?

In this study, we determined for the first time whether bees undergoing long distance transportation have higher $\mathrm{JH}$ levels (aging prematurely) and whether their hypopharyngeal gland sizes, total protein content in head or thorax, and lipid content in abdomen are smaller or lower due to transportation. Our hypothesis was that either due to higher mortality of older bees during transportation or loss of them due to drifting after transportation, or due to inadequate pollen consumption by young bees, we should see higher JH titers, smaller HPGs, lower protein content in heads and thorax, and lower lipid content in abdomen, in the bees experiencing transportation.

\section{Materials and Methods}

2.1. General Methods. A group of "transported" (T) honey bee colonies were moved to another location (CA trial), or traveled a round trip and returned to the original location (GA, MI trials). A group of "stationary" (S) colonies were not moved and served as the control. About 8-16 days prior to the transportation of bees, newly emerged bees from strong colonies were obtained by incubating sealed brood in make-shift "incubators" $\left(34 \pm 2^{\circ} \mathrm{C}, 50 \% \mathrm{RH}, \mathrm{CA}\right.$ and GA trial), or a laboratory incubator $\left(34 \pm 1^{\circ} \mathrm{C}, \mathrm{MI}\right.$ trial). The incubating area was in a bathroom with 1-2 space heaters and a thermostat controlled power strip that powered the heater(s). Workers were obtained from a source colony (300704 per colony), painted with Testor's color paint and split equally into two subgroups. One subgroup was introduced into a $\mathrm{T}$ colony, and the other subgroup was introduced into an $\mathrm{S}$ colony. Each of the $\mathrm{S}$ and $\mathrm{T}$ colonies receiving the same group of workers was termed a "colony-pair." This controlled any possible genetic differences among workers [21]. Any differences in measured parameters would be due to the treatment regime (transported or not), because colony differences (amount of food and brood) were controlled by having each colony-pairs as similar as possible in each trial. In each trial, for each total number of colony-pairs $(N=6$ to 12), we obtained brood from $N+3$ colonies to insure there were enough newly emerged bees for each colony-pair and did not use bees from the three lowest yielded colonies. Each colony pair therefore received bees from a single source colony.
Bee Bleeding. Hemolymph was taken for JH titer measurement. Sampled workers were bled according to established procedures [22]. Briefly, a small hole was pricked with a bent insect pin between the 4th and 5th abdomen segment of sampled bees. The hemolymph was collected in a capillary tube (Drummond Wiretrol 1 to $5 \mu \mathrm{L}$, Drummond Scientific company, USA) and then measured to the nearest $0.5 \mathrm{~mm}$ with a ruler and mixed with $500 \mu \mathrm{L}$ of acetonitrile (EM Science) in a $12 \times 125 \mathrm{~mm}$ culture tube with a Teflon-lined lid. The length of hemolymph was then converted to volume by knowing the calibrated mark $(5 \mu \mathrm{L})$ as $27 \mathrm{~mm}$ long.

Juvenile Hormone Titer Measurement. Juvenile hormone (JH) was extracted from the hemolymph and assayed with established procedures [9]. Briefly, JH III in the hemolymph sample was extracted with $1 \mathrm{~mL}$ hexane (twice), then the pooled hexane was evaporated using a vacuum centrifuge (Speed Vac Plus SC110; Savant Instrument Inc., Holbrook, NY) linked to a condenser (Savant SS21), which trapped the solvent at $-98^{\circ} \mathrm{C}$. The dried $\mathrm{JH}$ in the sample tube was dissolved in $100 \mu \mathrm{L}$ of methanol, and a $20 \mu \mathrm{L}$ aliquot (in duplicate) was taken out, dried, and mixed with $200 \mu \mathrm{L}$ of gel-phosphate-buffered-saline-Tritone ( $\mathrm{pH}$ 7.3) containing anti-JH antiserum (1:14,000 dilution, generous gift from David Borst) and about 10,000 DPM of [10-3H(N)]-JH (Perkin Elmer, $647.5 \mathrm{Gbq} / \mathrm{mmol}$ ). The mixture was incubated at room temperature for $2 \mathrm{~h}$, and then $0.5 \mathrm{~mL}$ of dextran-coated charcoal suspension (Sigma) was added to each sample tube to absorb the unbound JH. This mixture was incubated in an ice-water mixture for $2.5 \mathrm{~min}$ and then centrifuged ( $2000 \mathrm{~g}$ for $3 \mathrm{~min}$ ). The supernatant, which contained bound $\mathrm{JH}$, was decanted into a glass scintillation vial. Liquid scintillation counting was performed using a Packard 2100TR. A standard curve with various amounts (0, $3,10,30,100,300,1,000,3,000$, and 10,000 pg) of standard JH (Sigma) was run each day. KaleidaGraph (Synergy Software, PA, USA) was used to generate a standard curve. Five parameters for the standard curve were obtained by using DPM bound as the dependent variable, JH amount (after log transformation) as the independent variable, using nonlinear regression. The five-parameter formula was described in [22]. Excel (Microsoft, USA) was used to calculate the amount of JH in each sample, by reversing the five-parameter formula (solving for JH with known DPM and the five fitted parameters).

Hypopharyngeal Gland Size Measurement. Hypopharyngeal glands were dissected in $0.9 \%$ saline under a dissecting microscope (Olympus SZ12, x32) and then photographed by a digital camera (QImaging Go-3). We then used Image-Pro express 6.0 (Nikon, USA) to measure the width and length of five acini for each bee. The volume of each acinus was calculated as $1 / 6 \times 3.14 \times$ length $\times$ width [23].

Protein Content in Head and Thorax Measurement. Protein content in head and thorax was measured similar to hemolymph protein $[24,25]$. Briefly, the head or thorax (excluding wings and legs) was removed with a pair of 
micro-scissor from individual bees and crushed in $500 \mu \mathrm{L}$ $1 \mathrm{~N} \mathrm{NaOH}$ using a plastic pestle and incubated overnight. The solution was then vortexed and centrifuged for $5 \mathrm{~min}$ at $2000 \mathrm{~g}$. The solution was then diluted 25 times and $10 \mu \mathrm{L}$ was loaded (in duplicate) to a cell in a 96-cell plate, each cell was then added $200 \mu \mathrm{L}$ Bio-Rad Protein dye (Bio-Rad, USA) after $4 \mathrm{X}$ dilution. The absorbance of the sample was measured at $595 \mathrm{~nm}$ using a Molecular Devices Softmax Pro5 Microplate Spectrophotometer. The amount of protein in each sample was calculated by comparing to a standard curve run each day using known amounts of bovine serum albumin (SigmaAldrich, USA).

Lipid Content in Abdomen Measurement. Lipid content in abdomen was measured similar to Toth and Robinson [20], using a colorimetric assay. Briefly, the abdomen was cut from individual bees and the internal organs (digestive tract and the sting apparatus) removed, leaving the cuticle with adhered fat body tissue. Each sample was then homogenized in a mechanical homogenizer (Polytron PT 2100, setting of 12) in $2 \mathrm{~mL} 2: 1$ chloroform : methanol [26] and allowed to extract overnight. The extract was then mixed with $0.5 \mathrm{~mL}$ water and centrifuged at $5000 \mathrm{~g}$ for $10 \mathrm{~min}$. The top phase (water) was removed and discarded. The organic phase was filtered through glass wool and adjusted to a total volume of $2 \mathrm{~mL}$. A $100 \mu \mathrm{L}$ subsample of each lipid extract was dried completely, $0.2 \mathrm{~mL}$ concentrated sulfuric acid was added, and samples were heated in boiling water for $10 \mathrm{~min}$. Then, $2.0 \mathrm{~mL}$ vanillin reagent $(0.6 \%$ in $85 \%$ phosphoric acid) was added to each sample, which was vortexed and dark-incubated for $15 \mathrm{~min}$ to allow pink color formation. Absorbance at $525 \mathrm{~nm}$ was measured for each sample using a Molecular Devices Spectra Max 190 multiwell spectrophotometer (Sunnyville, CA, USA). A standard curve using known amounts of pure cholesterol was used to calculate lipid amounts. Each lipid sample was measured in duplicates, and average values were used for subsequent analysis.

\subsection{Details of Three Trials}

California (CA) Trial. Twelve colony-pairs were used; the S and $\mathrm{T}$ groups at Bakersfield, CA.

Newly emerged bees from source colonies were obtained and painted on March 12-13th 2008 then equally divided into two groups. One group was introduced into a $\mathrm{T}$ colony and the other half into an S colony. Over 6,000 bees were painted and introduced in two days (150 to 344 bees per colony, 24 colonies). The $\mathrm{S}$ group stayed in Bakersfield, CA, while the T group was moved to Florida during a 4 day period (March 14-17th) with a total distance traveled as $4,000 \mathrm{~km}$. On March 18th, 6-7-day-old marked workers were sampled with soft forceps by two people (one at FL, another at CA), and placed them on dry ice, stored at $-80^{\circ} \mathrm{C}$, then shipped to Michigan State University (East Lansing, MI) for analysis.

Ten bees were thawed on ice, and blood removed for $\mathrm{JH}$ determination for each colony of 11 colony-pairs $(10 \times$ $11 \times 2=220$ bees) because one colony was lost due to robbing. A previous study has indicated that blood obtained this way showed lower $\mathrm{JH}$ titers compared to that of fresh bees, but the differences between nurses and foragers were maintained (Z. Y. Huang and K. Ahn, unpublished data). Ten bees were dissected for each colony of 9 colony-pairs for HPG size measurement $(10 \times 9 \times 2=180$ bees $)$. Ten bees were measured in each colony of 4 colony-pairs for lipid content in abdomen analysis $(10 \times 4 \times 2=80$ samples $)$.

Georgia (GA) Trial. Twelve colony-pairs were used for a second trial in Boston, GA. Nearly 6,000 bees (200 to 352 bees per colony) were painted and introduced into 24 colonies on April 18th and 19th, 2008 (but only the first cohort of bees, marked a different color, was used for sampling). The $\mathrm{T}$ colonies were moved to Sunfield, Michigan (07:00 April 20th to 15:00 April 21st), rested for one day (April 22nd), and then returned to Boston, GA (12:00 April 23rd to 16:30 April 24th), with a round trip of $3,250 \mathrm{~km}$. The bees had opportunity to fly and forage on April 22nd, 2008, while in Michigan.

On April 25th, ten bees ( 8 days old) were sampled with soft forceps, put on dry ice for hypothermic anesthesia, and bled immediately (within $30 \mathrm{~min}$ ) in each colony of the 12 colony-pairs for $\mathrm{JH}$ determination $(10 \times 12 \times 2=$ 240 bees). The bled bees were then individually labeled and frozen on dry ice, brought to Michigan, then stored at $-80^{\circ} \mathrm{C}$ freezer until analysis. Since some heads were used to protein measurement, we only analyzed bees from 4 colony-pairs ( 10 $\times 4 \times 2=80$ samples) for HPG. Ten bees were analyzed in each colony of 8 colony-pairs for protein content in head and thorax $(10 \times 8 \times 2=160$ heads and 160 thoraces $)$. Ten bees were analyzed in each colony of 4 colony-pairs for lipid content in abdomen $(10 \times 4 \times 2=80$ samples $)$.

Michigan (MI) Trial. Six colony-pairs were used for S and T groups in East Lansing, MI. Newly emerged workers (192 to 336 bees per colony) were introduced to the colonies after being painted on May 19th of 2008 (1,430 bees) and 29th of 2008 (2,400 bees). These two groups were intended to be sampled as 17- and 7-day-old bees, respectively, on the date of sampling (June 4th). Transportation was conducted by driving the T colonies about $900 \mathrm{~km}$ per day (approximately 08:00 to 17:00), with a total of $2,750 \mathrm{~km}$ round trip (from June 1 st to June $3 \mathrm{rd}$ ).

On June 4th, paint-marked 7- and 17-day-old bees were collected by using soft forceps, bled, and stored at $-80^{\circ} \mathrm{C} \mathrm{JH}$ titers, HPG size, protein, and lipid analysis.

Ten 7 - and 17-day-old bees were sampled in every colony of the 6 colony-pairs for JH determination $(10 \times 6 \times 2=$ 240 bees each age). Ten bees were dissected for HPG size measurement from each colony of the 6 colony-pairs $(5 \times$ $10 \times 6 \times 2=120$ samples). Ten bees were sampled in every colony of 5 colony-pairs for protein content in head analysis $(10 \times 5 \times 2=100$ heads $)$. Ten bees were measured in each colony of the 6 colony-pairs for lipid content in abdomen $(10 \times 6 \times 2=120$ abdomens $)$.

2.3. Statistical Analyses. Juvenile hormone titers were transformed (logarithmic $(\mathrm{JH}+1)$ ) to meet the requirements 
of parametric analysis. Differences in JH titers, HPG size, total protein content in head or thorax, and abdomen lipid for bees in $\mathrm{S}$ and $\mathrm{T}$ groups were analyzed by ANOVA by State View (SAS Institute, NC, USA). Each colony-pair was analyzed separately as an independent comparison, but all colonies in each trial were also analyzed together to compare the overall effect of transportation.

\section{Results}

\subsection{JH Titers in Hemolymph}

CA Trial. There were no significant differences between the $\mathrm{S}$ and $\mathrm{T}$ groups, when all 11 colony-pairs were analyzed together by ANOVA (for $F$ and $P$ values, see Table 1), although colony-pairs 2 and 10 showed differences in $\mathrm{JH}$ titers when analyzed as two separate single colony-pairs (Figure 1(a)).

GA Trial. There were no significant differences between the $\mathrm{S}$ and $\mathrm{T}$ groups when all 12 colony-pairs were analyzed together (Table 1), although S showed significantly higher $\mathrm{JH}$ titers than T colony in colony-pair 8 (Figure 1(b)).

MI Trial. There were no significant differences between the $\mathrm{S}$ and $\mathrm{T}$ groups in 7-day-old bees when all 6 colony-pairs were analyzed together (Table 1), although colony-pairs 3, 4, and 6 showed significant differences between the two groups (Figure 1(c)).

In 17-day-old bees, no significant differences were detected between $S$ and $T$ groups when all 6 colony-pairs were analyzed together by ANOVA (Table 1), although the T had significantly higher JH titers than $\mathrm{S}$ colony in colony-pair 1 (Figure 1(d)).

\subsection{Volume of HPG Acini}

CA Trial. There were significant differences in the volume of HPG acini between the $\mathrm{S}$ and $\mathrm{T}$ groups in the overall analysis (Table 1). If it was analyzed in each colony-pair, six pairs (except colony-pairs 3, 5, and 7) showed significant differences between the $\mathrm{S}$ and $\mathrm{T}$ colonies in the volume of HPG acini (Figure 2(a)).

GA Trial. Either by overall analysis (Table 1) or each colonypair (Figure 2(b)), results showed that the volumes of HPG acini in the $\mathrm{S}$ group were larger than the $\mathrm{T}$ group.

MI Trial. When all colony-pairs were analyzed together by ANOVA, results showed that the volumes of HPG acini were significantly different between the $\mathrm{S}$ and $\mathrm{T}$ groups (Table 1 ) in 7-day-old bees. Although in colony-pair 5 the difference was reversed (Figure 2(c)).

In 17-day-old bees, the volume of HPG acini in S groups was significantly larger than $\mathrm{T}$ (Table 1 ), although there were no significantly differences in colony-pair 4, 5, and 6 (Figure 2(d)).

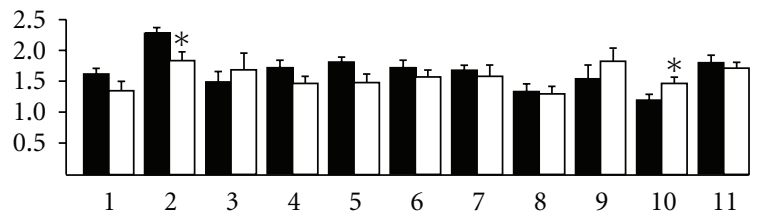

(a) $\mathrm{CA}$

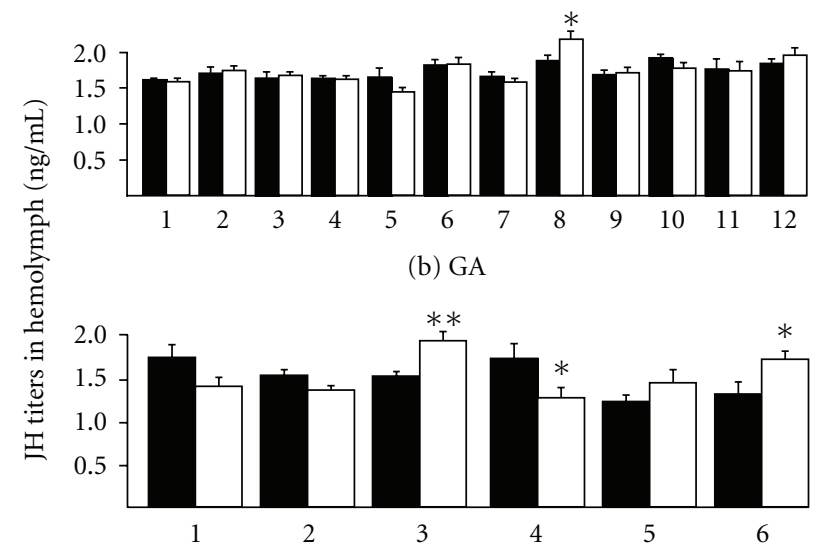

(c) MI 7-day-old

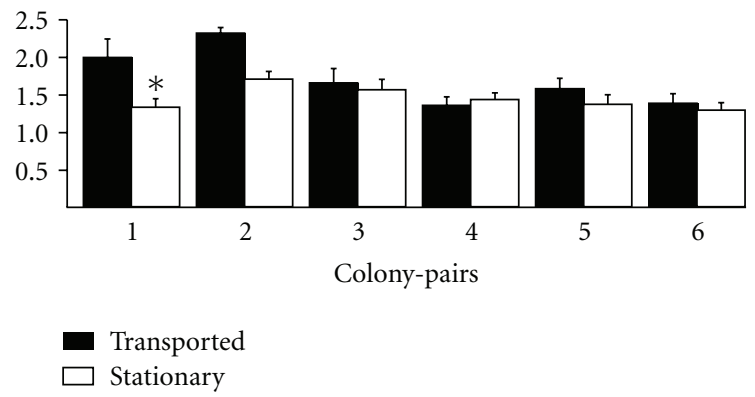

(d) MI 17-day-old

FIGURE 1: Hemolymph juvenile hormone titers (mean \pm SE) in worker honey bees experiencing transportation (solid) or no transportation (open) in California (a), Georgia (b), or Michigan ((c), (d)). Workers were 6-7 days old for CA, 8 days for GA and noted in figure for MI. $N=10$ bees for each colony. Each number represents a colony-pair that hosted genetically similar workers from a source colony. $A^{*}$ inside the open bar indicates that the $\mathrm{JH}$ titers between the two colonies within that colony-pair were significantly different ( $t$-test, $P<0.05)$, while $* *$ denotes highly significant $(P<0.01)$.

\subsection{Protein Content in Head}

GA Trial. When all 8 colony-pairs were analyzed together, ANOVA detected a significant reduction in head protein in the T group (Table 1), although only three colony-pairs (1, 3 , and 8) showed that $S$ groups had significantly higher protein content in heads when analyzed as single colonypairs (Figure 3(a)).

MI Trial. For 7-day-old bees, when either analyzed together (Table 1) or as single colony-pairs (Figure 3(b)), there were 
TABLe 1: $F$ and $P$ values from analysis of variance (ANOVA) conducted for each trial and each parameter, with "ns" denoting nonsignificant $(P>0.05)$. JH titers were transformed $(\log (\mathrm{JH}+1))$ before ANOVA. "Colony source" refers to the differences due to genetic background of source colonies, "transportation" refers to the difference between transported and stationary colonies, and interaction refers to the effect of two (genetics X transportation status). Workers in CA were 6-7 days old, in GA were 8 days old, and those in MI were either 7 or 17 days old.

\begin{tabular}{|c|c|c|c|c|c|}
\hline Item & Trial & Effect & DF & $F$ & $P$ \\
\hline \multirow{12}{*}{$\mathrm{JH}$ titers in hemolymph } & \multirow{3}{*}{ CA } & Colony source & 10,186 & 5.55 & $<0.01$ \\
\hline & & Transportation & 1,186 & 1.70 & ns \\
\hline & & Interaction & 10,186 & 1.77 & ns \\
\hline & \multirow{3}{*}{ GA } & Colony source & 11,214 & 5.98 & $<0.01$ \\
\hline & & Transportation & 1,214 & 0.01 & ns \\
\hline & & Interaction & 11,214 & 1.24 & ns \\
\hline & \multirow{3}{*}{ MI 7-day-old } & Colony source & 5,106 & 2.48 & 0.04 \\
\hline & & Transportation & 1,106 & 0.02 & ns \\
\hline & & Interaction & 5,106 & 5.31 & $<0.01$ \\
\hline & \multirow{3}{*}{ MI 17-day-old } & Colony source & 5,99 & 2.54 & 0.03 \\
\hline & & Transportation & 1,99 & 6.08 & 0.02 \\
\hline & & Interaction & 5,99 & 1.82 & ns \\
\hline \multirow{12}{*}{ Volume of HPG acini } & \multirow{3}{*}{ CA } & Colony source & 8,162 & 6.65 & $<0.01$ \\
\hline & & Transportation & 1,162 & 62.65 & $<0.01$ \\
\hline & & Interaction & 8,162 & 1.84 & ns \\
\hline & \multirow{3}{*}{ GA } & Colony source & 3,72 & 0.52 & ns \\
\hline & & Transportation & 1,72 & 43.39 & $<0.01$ \\
\hline & & Interaction & 3,72 & 0.23 & ns \\
\hline & \multirow{3}{*}{ MI 7-day-old } & Colony source & 5,108 & 8.03 & $<0.01$ \\
\hline & & Transportation & 1,108 & 35.44 & $<0.01$ \\
\hline & & Interaction & 5,108 & 5.93 & $<0.01$ \\
\hline & \multirow{3}{*}{ MI 17-day-old } & Colony source & 5,108 & 5.11 & $<0.01$ \\
\hline & & Transportation & 1,108 & 18.17 & $<0.01$ \\
\hline & & Interaction & 5,108 & 4.16 & $<0.01$ \\
\hline \multirow{9}{*}{ Protein content in head } & \multirow{3}{*}{ GA } & Colony source & 7,144 & 17.06 & $<0.01$ \\
\hline & & Transportation & 1,144 & 12.96 & $<0.01$ \\
\hline & & Interaction & 7,144 & 1.89 & ns \\
\hline & \multirow{3}{*}{ MI 7-day-old } & Colony source & 4,90 & 12.27 & $<0.01$ \\
\hline & & Transportation & 1,90 & 1.24 & ns \\
\hline & & Interaction & 4,90 & 0.63 & ns \\
\hline & \multirow{3}{*}{ MI 17-day-old } & Colony source & 4,90 & 1.00 & ns \\
\hline & & Transportation & 1,90 & 6.55 & $<0.01$ \\
\hline & & Interaction & 4,90 & 2.91 & $<0.03$ \\
\hline \multirow{3}{*}{ Protein content in thorax } & \multirow{3}{*}{ GA } & Colony source & 7,144 & 13.10 & $<0.01$ \\
\hline & & Transportation & 1,144 & 1.86 & ns \\
\hline & & Interaction & 7,144 & 1.83 & ns \\
\hline \multirow{12}{*}{ Lipid content in abdomen } & \multirow{3}{*}{$\mathrm{CA}$} & Colony source & 3,72 & 2.44 & ns \\
\hline & & Transportation & 1,72 & 0.02 & ns \\
\hline & & Interaction & 3,72 & 4.60 & $<0.01$ \\
\hline & \multirow{3}{*}{ GA } & Colony source & 3,72 & 10.54 & ns \\
\hline & & Transportation & 1,72 & 2.47 & ns \\
\hline & & Interaction & 3,72 & 5.09 & $<0.01$ \\
\hline & \multirow{3}{*}{ MI 7-day-old } & Colony source & 5,108 & 4.84 & $<0.01$ \\
\hline & & Transportation & 1,108 & 2.09 & ns \\
\hline & & Interaction & 5,108 & 1.54 & ns \\
\hline & \multirow{3}{*}{ MI 17-day-old } & Colony source & 5,108 & 1.42 & ns \\
\hline & & Transportation & 1,108 & 2.53 & ns \\
\hline & & Interaction & 5,108 & 1.27 & ns \\
\hline
\end{tabular}




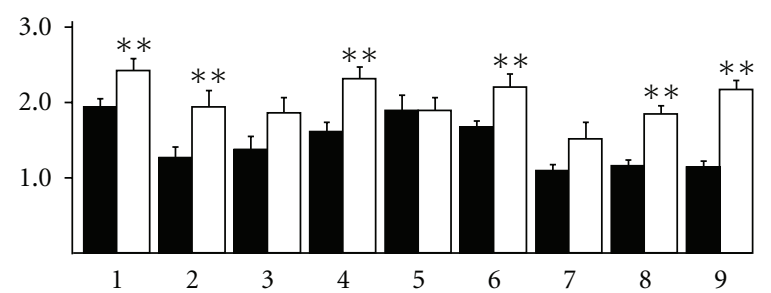

(a) $\mathrm{CA}$

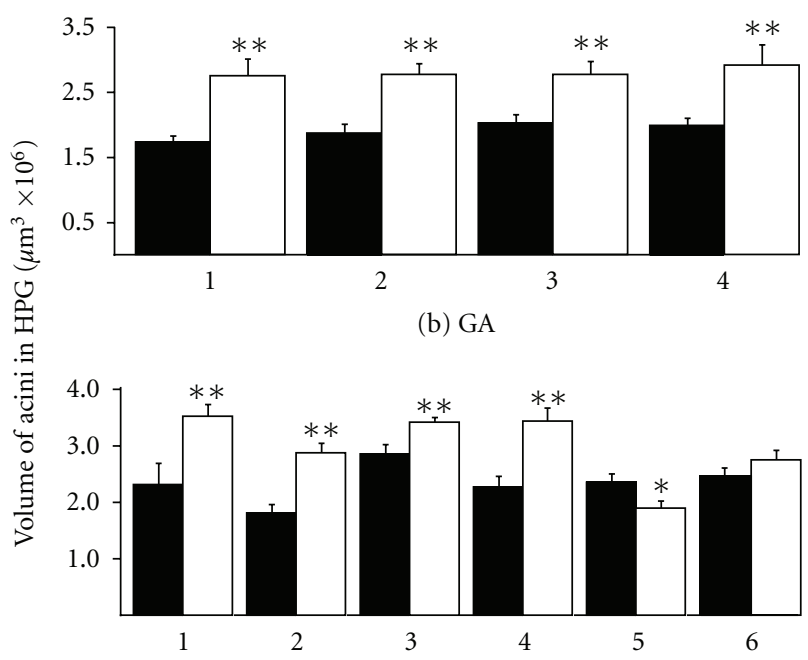

(c) MI 7-day-old

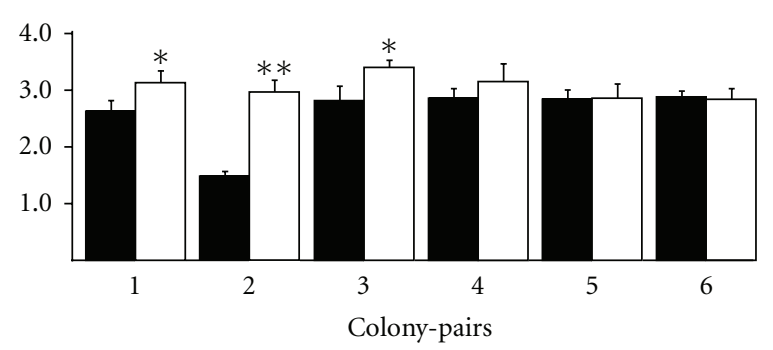

Transported Stationary

(d) MI 17-day-old

FIGURE 2: Size of hypopharyngeal glands (mean \pm SE) measured as volume of gland acini in worker honey bees experiencing transportation (solid) or no transportation (open) in California (a), Georgia (b), or Michigan ((c), (d)). For more details, see Figure 1 legend.

no significant differences between the $\mathrm{S}$ and $\mathrm{T}$ groups in 7day-old bees.

For 17-day-old bees, there were no significant differences when analyzed together (Table 1), although colony-pair 3 showed significant differences between $\mathrm{S}$ and $\mathrm{T}$ (Figure 3(c)).

\subsection{Protein Content in Thorax}

GA Trial. There were no significantly differences between $\mathrm{S}$ and $\mathrm{T}$ groups in thorax protein content when analyzed together (Table 1), although the $\mathrm{S}$ colonies were significantly higher than $\mathrm{T}$ colonies in colony-pairs 2 and 4 (Figure 3(d)).

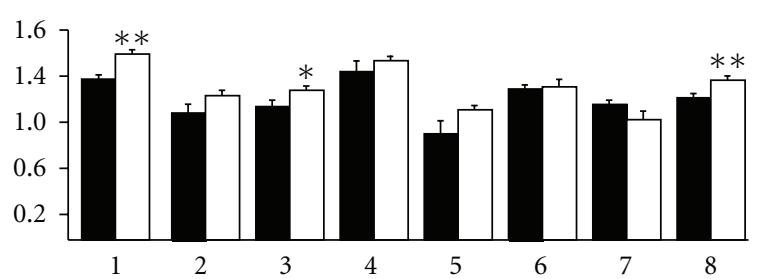

(a) GA head

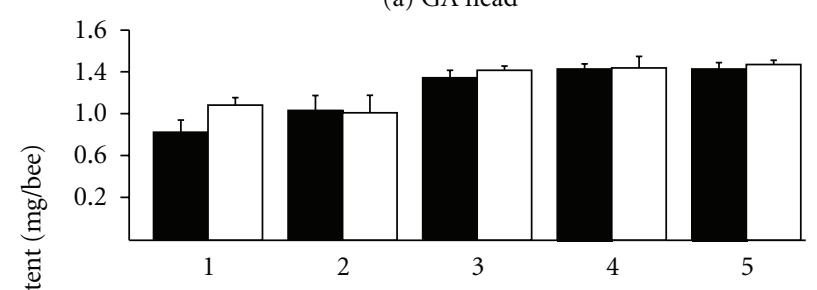

(b) MI 7-day-old head

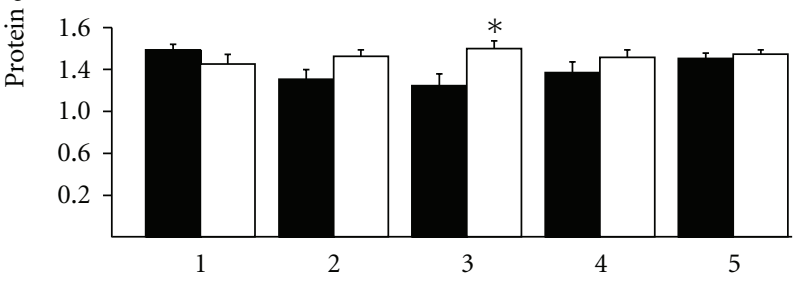

(c) MI 17-day-old head

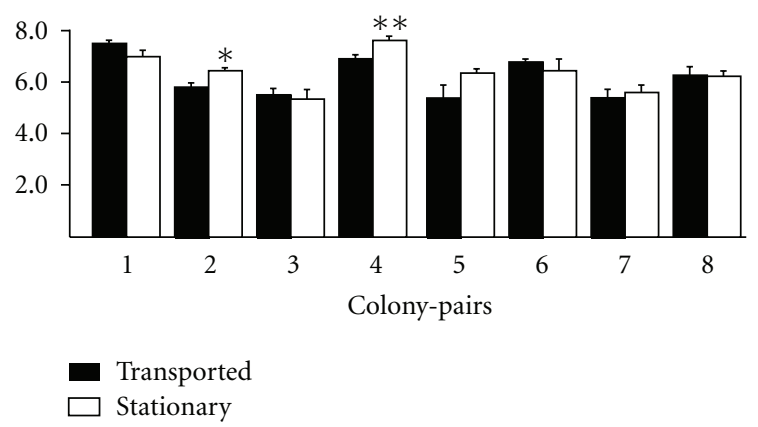

(d) GA thorax

FIGURE 3: Protein content (mean \pm SE) in worker honey bees experiencing transportation (solid) or no transportation (open) in heads ((a), (b), (c)) or thorax (d). For more details, see Figure 1 legend.

\subsection{Lipid Content in Abdomen}

CA Trial. There were no significant differences between the $\mathrm{S}$ and $\mathrm{T}$ groups (Table 1), although colony-pair 3 showed a significant difference between the two groups (Figure 4(a)).

GA Trial. There were no significant differences detected between $S$ and T group when all 4 colony-pairs were analyzed together (Table 1), although S had higher lipid content in abdomen than $\mathrm{T}$ in colony-pair 1 (Figure $4(\mathrm{~b})$ ).

MI Trial. For 7-day-old bees, there were no significant differences between $\mathrm{S}$ and $\mathrm{T}$ groups in lipid content in abdomen (Table 1), individual pairs also did not show any differences (Figure 4(c)). 


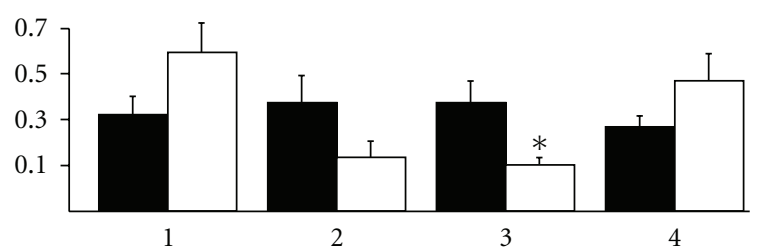

(a) $\mathrm{CA}$

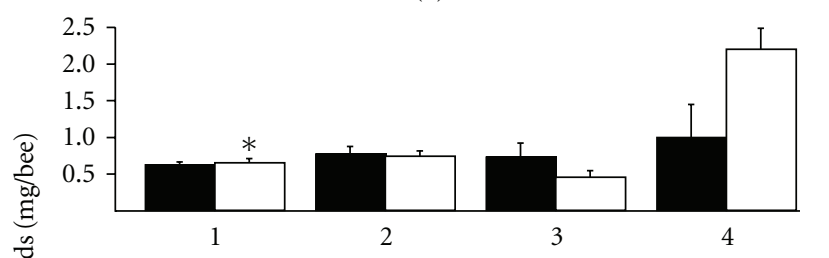

(b) GA

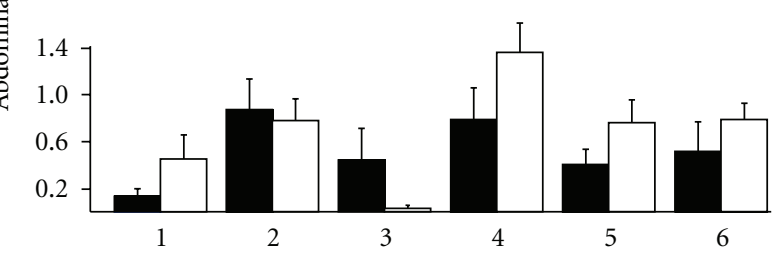

(c) MI 7-day-old

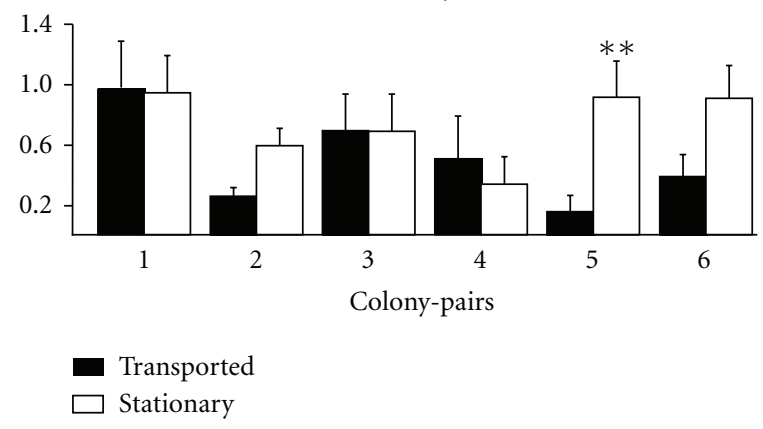

(d) MI 17-day-old

FIGURE 4: Lipid content (mean \pm SE) in worker honey bees experiencing transportation (solid) or no transportation (open) in California (a), Georgia (b), or Michigan ((c), (d)). For more details, see Figure 1 legend.

For 17-day-old bees, there were no significant differences between $S$ and $T$ groups when all 6 colony-pairs were analyzed together (Table 1), although $\mathrm{S}$ had higher lipid content in abdomen than T (Figure $4(\mathrm{~d})$ ).

\section{Discussion}

The major finding from this study was that HPG sizes were consistently and negatively affected by transportation. Results showed that the volume of HPG acini were significantly smaller in bees from transported colonies than that from stationary ones (Figure 2). This was true for all three trials conducted in different locations, and also for both young (7-day-old) and old (17-day-old) bees in the Michigan trial. Previous studies have shown that consumption rate of protein diets had a positive correlation with the development of HPG $[27,28]$. In this study, the worker bees in $\mathrm{T}$ group showed consistently smaller HPG sizes, possibly due to their inability to find or consume pollen normally. It is also possible that trophallaxis was adversely affected such that the initial flow of jelly to very young bees (1-4 days old) from nurses occurred at a lower frequency such that normal HPG development was affected [16]. Yet another possibility is that the queen stopped laying during transportation and the overall level of brood pheromone would be lower in the transported colonies, and this could have affected their HPG development negatively. It is a bit surprising that 17day-old bees were also affected in their gland size, because these bees were 13 days old when the transportation took place in the MI trial. Workers should have attained their maximum gland size around 12-14 days old [29], however, transportation during this time period still significantly negatively impacted their gland size. It is possible that these 17-day-old bees were actively nursing brood during transportation but they were unable to balance their protein input with proper pollen feeding. This suggests that all in-hive workers (workers that are performing preforaging duties) are affected by transportation. It is puzzling that while HPG acini sizes showed consistent differences in all trials, the head protein or thorax protein content did not show the same pattern. Head protein includes HPG and brain, plus head salivary glands and muscles for the mandibles. Our data here suggest that HPG size responded more consistently to transportation stress. Thorax protein content mainly reflects the mass of the flight muscles, for some reason it also does not show a consistent effect. It is possible that HPGs respond more rapidly, but changes in head or thorax protein content have more variability and do not show the same sensitivity to stress-related events. A recent study also failed to find any differences in bees from healthy and colonies exhibiting colony collapse disorder (CCD) in weights or protein content of head, thorax, abdomen [30].

$\mathrm{JH}$ is well studied because it plays many roles in honey bees. It has been known to be involved in the queenworker caste differentiation during the larval stage [31, 32], in regulating the age-related division of labor in adult workers [33], and in determining aggression levels in workers [34]. $\mathrm{JH}$ titers are regulated by the changes in rate of $\mathrm{JH}$ biosynthesis and other processes, such as degradation and tissue uptake [35]. A previous study showed that JH levels in foragers also displayed diurnal changes. JH titers were at their lowest just before noon, slightly increased by late afternoon and peaked just before midnight [36]. Lin et al. provided the first evidence that $\mathrm{JH}$ titers changed rapidly when workers were removed from their normal social environment and manipulated experimentally [9]. Therefore, JH titers in hemolymph of honey bees were influenced by many factors.

In this study, there were no differences in $\mathrm{JH}$ titers between $\mathrm{S}$ and $\mathrm{T}$ groups, when all colony-pairs were analyzed together by ANOVA. This is contrary to our original hypothesis that transported bees should have higher $\mathrm{JH}$ titers than stationary bees. It is possible that our bees were too young ( $\leq 8$ days in all trials except MI 17-day-old bees) to observe an effect on JH. However, even in 17-day-old bees (Figure 1(d)), only colony-pair 1 showed significantly higher 
JH titers in the T group, while colony-pair 2 showed a trend but it was not significantly different. It is possible that $\mathrm{JH}$ is affected by too many factors and is not a good indicator for transportation-related stress. Alternatively, the transported bees did not experience a faster behavioral development as we originally hypothesized.

Toth and Robinson found that abdominal lipid stores in honey bees decline prior to the onset of foraging [20]. Before this study, we had hypothesized that lipid content in abdomen should be lower in transported bees, either due to faster behavioral development, or due to less pollen consumption during the long distance transportation. However, the data here showed that there were no significant differences between stationary and transported groups in their fat content. This agrees with the JH data, suggesting that transported bees did not experience a faster behavioral development.

Our study concentrated on younger bees in the colony, assuming that they would be more sensitive to transportation-generated disturbances. However, it might be that the older bees are more sensitive to this process. Foragers, for example, might experience higher mortality due to their higher metabolism, and also due to a lack of jelly fed to them during the transportation, as suggested by this study. We assumed that the physiological responses were maximal immediately after the transportation took place. However, it is possible that it might take 3-4 days for the effect to be manifested and we might therefore have missed effects on accelerated development. We also did not know how long the negative impact lasted on the transported bees or whether their glands would recover after another week. A laboratory proxy for long distance transportation is needed to further dissect the detailed mechanisms of transportation-induced stresses.

\section{Acknowledgments}

This project was funded by grants from North American Pollinator Protection Campaign (NAPPC), National Honey Board (NHB), Generating Research and Extension to meet Economic and Environmental Needs (GREEEN) at the Michigan State University, USDA NIFA AFRI "Managed Pollinator Coordinated Agricultural Project" (2009-8511805718) (to Z. Y. Huang), and the USDA-ARS Areawide Program to improve bee health (to J. Pettis). The authors thank Nathan Rice, Frank Eischen, Dennie Best, and Oren Best for their help in the course of this project and anonymous reviewers for suggestions on this paper.

\section{References}

[1] N. Gallai, J. M. Salles, J. Settele, and B. E. Vaissière, "Economic valuation of the vulnerability of world agriculture confronted with pollinator decline," Ecological Economics, vol. 68, no. 3, pp. 810-821, 2009.

[2] M. Navajas, D. L. Anderson, L. I. De Guzman et al., "New Asian types of Varroa destructor: a potential new threat for world apiculture," Apidologie, vol. 41, no. 2, pp. 181-193, 2010.
[3] Y. P. Chen and Z. Y. Huang, "Nosema ceranae, a newly identified pathogen of Apis mellifera in the USA and Asia," Apidologie, vol. 41, no. 3, pp. 364-374, 2010.

[4] M. Miles, "The effects of spinosad, a naturally derived insect control agent to the honeybee," Bulletin of Insectology, vol. 56, no. 1, pp. 119-124, 2003.

[5] R. M. Johnson, Z. Y. Huang, and M. R. Berenbaum, "Role of detoxification in Varroa destructor (Acari: Parasitidae) tolerance of the miticide tau-fluvalinate," International Journal of Acarology, vol. 36, no. 1, pp. 1-6, 2010.

[6] G. E. Robinson, "Regulation of honey bee age polyethism by juvenile hormone," Behavioral Ecology and Sociobiology, vol. 20, no. 5, pp. 329-338, 1987.

[7] G. E. Robinson and R. E. Page, "Genetic determination of nectar foraging, pollen foraging, and nest-site scouting in honey bee colonies," Behavioral Ecology and Sociobiology, vol. 24, no. 5, pp. 317-323, 1989.

[8] Z. Y. Huang, G. E. Robinson, and D. W. Borst, "Physiological correlates of division of labor among similarly aged honey bees," Journal of Comparative Physiology A, vol. 174, no. 6, pp. 731-739, 1994.

[9] H. Lin, C. Dusset, and Z. Y. Huang, "Short-term changes in juvenile hormone titers in honey bee workers due to stress," Apidologie, vol. 35, no. 3, pp. 319-327, 2004.

[10] K. R. Guidugli, A. M. Nascimento, G. V. Amdam et al., "Vitellogenin regulates hormonal dynamics in the worker caste of a eusocial insect," FEBS Letters, vol. 579, no. 22, pp. 4961-4965, 2005.

[11] G. V. Amdam, Z. L. P. Simões, A. Hagen et al., "Hormonal control of the yolk precursor vitellogenin regulates immune function and longevity in honeybees," Experimental Gerontology, vol. 39, no. 5, pp. 767-773, 2004.

[12] S. C. Seehuus, K. Norberg, U. Gimsa, T. Krekling, and G. V. Amdam, "Reproductive protein protects functionally sterile honey bee workers from oxidative stress," Proceedings of the National Academy of Sciences of the United States of America, vol. 103, no. 4, pp. 962-967, 2006.

[13] M. Corona, R. A. Velarde, S. Remolina et al., "Vitellogenin, juvenile hormone, insulin signaling, and queen honey bee longevity," Proceedings of the National Academy of Sciences of the United States of America, vol. 104, no. 17, pp. 7128-7133, 2007.

[14] C. R. Ribbands, The Behavior and Social Life of Honeybees, Bee Research Association Ltd., London, UK, 1953.

[15] R. E. Snodgrass, Anatomy of the Honey Bee, Comstock, Cornell University Press, Ithaca, NY, USA, 1956.

[16] K. Crailsheim, "The flow of jelly within a honeybee colony," Journal of Comparative Physiology B, vol. 162, no. 8, pp. 681689, 1992.

[17] Z. Y. Huang and G. W. Otis, "Factors determining hypopharyngeal gland activity of worker honey bees (Apis mellifera L.)," Insectes Sociaux, vol. 36, no. 4, pp. 264-276, 1989.

[18] N. Hrassnigg and K. Crailsheim, "Adaptation of hypopharyngeal gland development to the brood status of honeybee (Apis mellifera L.) colonies," Journal of Insect Physiology, vol. 44, no. 10, pp. 929-939, 1998.

[19] D. I. Wang and F. E. Moeller, "Histological comparisons of the development of hypopharyngeal glands in healthy and Nosema-infected worker honey bees," Journal of Invertebrate Pathology, vol. 14, no. 2, pp. 135-142, 1969.

[20] A. L. Toth and G. E. Robinson, "Worker nutrition and division of labour in honeybees," Animal Behaviour, vol. 69, no. 2, pp. 427-435, 2005. 
[21] T. Giray, E. Guzmán-Novoa, C. W. Aron, B. Zelinsky, S. E. Fahrbach, and G. E. Robinson, "Genetic variation in worker temporal polyethism and colony defensiveness in the honey bee, Apis mellifera," Behavioral Ecology, vol. 11, no. 1, pp. 44$55,2000$.

[22] Z.-Y. Huang and G. E. Robinson, "Regulation of honey bee division of labor by colony age demography," Behavioral Ecology and Sociobiology, vol. 39, no. 3, pp. 147-158, 1996.

[23] F. W. Preston, “The volume of an egg”, The AUK, vol. 91, pp. 132-138, 1974.

[24] A. V. Hanley, Z. Y. Huang, and W. L. Pett, "Effects of dietary transgenic Bt corn pollen on larvae of Apis mellifera and Galleria mellonella," Journal of Apicultural Research, vol. 42, no. 4, pp. 77-81, 2003.

[25] Z. Y. Huang, A. V. Hanley, W. L. Pett, M. Langenberger, and J. J. Duan, "Field and semifield evaluation of impacts of transgenic canola pollen on survival and development of worker honey bees," Journal of Economic Entomology, vol. 97, no. 5, pp. 15171523, 2004.

[26] E. G. Perkins, Analysis of Lipids and Lipoproteins, American Oil Chemists' Society, Champaign, Ill, USA, 1975.

[27] G. DeGrandi-Hoffman, Y. Chen, E. Huang, and M. H. Huang, "The effect of diet on protein concentration, hypopharyngeal gland development and virus load in worker honey bees (Apis mellifera L.)," Journal of Insect Physiology, vol. 56, no. 9, pp. 1184-1191, 2010.

[28] A. A. Al-Ghamdi, A. M. Al-Khaibari, and M. O. Omar, "Consumption rate of some proteinic diets affecting hypopharyngeal glands development in honeybee workers," Saudi Journal of Biological Sciences, vol. 18, no. 1, pp. 73-77, 2011.

[29] G. E. King, The larger glands in the worker honey-bee, a correlation of activity with age and with physiological functioning [Ph.D. thesis], University of Illinois, Urbana, Ill, USA, 1933.

[30] D. Vanengelsdorp, J. D. Evans, C. Saegerman et al., "Colony collapse disorder: a descriptive study," PloS one, vol. 4, no. 8, article e6481, 2009.

[31] A. Rachinsky and K. Hartfelder, "Corpora allata activity, a prime regulating element for caste-specific juvenile hormone titre in honey bee larvae (Apis mellifera carnica)," Journal of Insect Physiology, vol. 36, no. 3, pp. 189-194, 1990.

[32] A. Rachinsky, C. Strambi, A. Strambi, and K. Hartfelder, "Caste and metamorphosis: hemolymph titers of juvenile hormone and ecdysteroids in last instar honeybee larvae," General and Comparative Endocrinology, vol. 79, no. 1, pp. 3138, 1990.

[33] G. E. Robinson, "Regulation of division of labor in insect societies," Annual review of entomology. Vol. 37, pp. 637-665, 1992.

[34] A. N. Pearce, Z. Y. Huang, and M. D. Breed, "Juvenile hormone and aggression in honey bees," Journal of Insect Physiology, vol. 47, no. 11, pp. 1243-1247, 2001.

[35] S. S. Tobe and B. Stay, "Structure and regulation of the corpus allatum," Advances in Insect Physiology, vol. 18, no. C, pp. 305432, 1985.

[36] M. M. Elekonich, D. J. Schulz, G. Bloch, and G. E. Robinson, "Juvenile hormone levels in honey bee (Apis mellifera L.) foragers: foraging experience and diurnal variation," Journal of Insect Physiology, vol. 47, no. 10, pp. 1119-1125, 2001. 

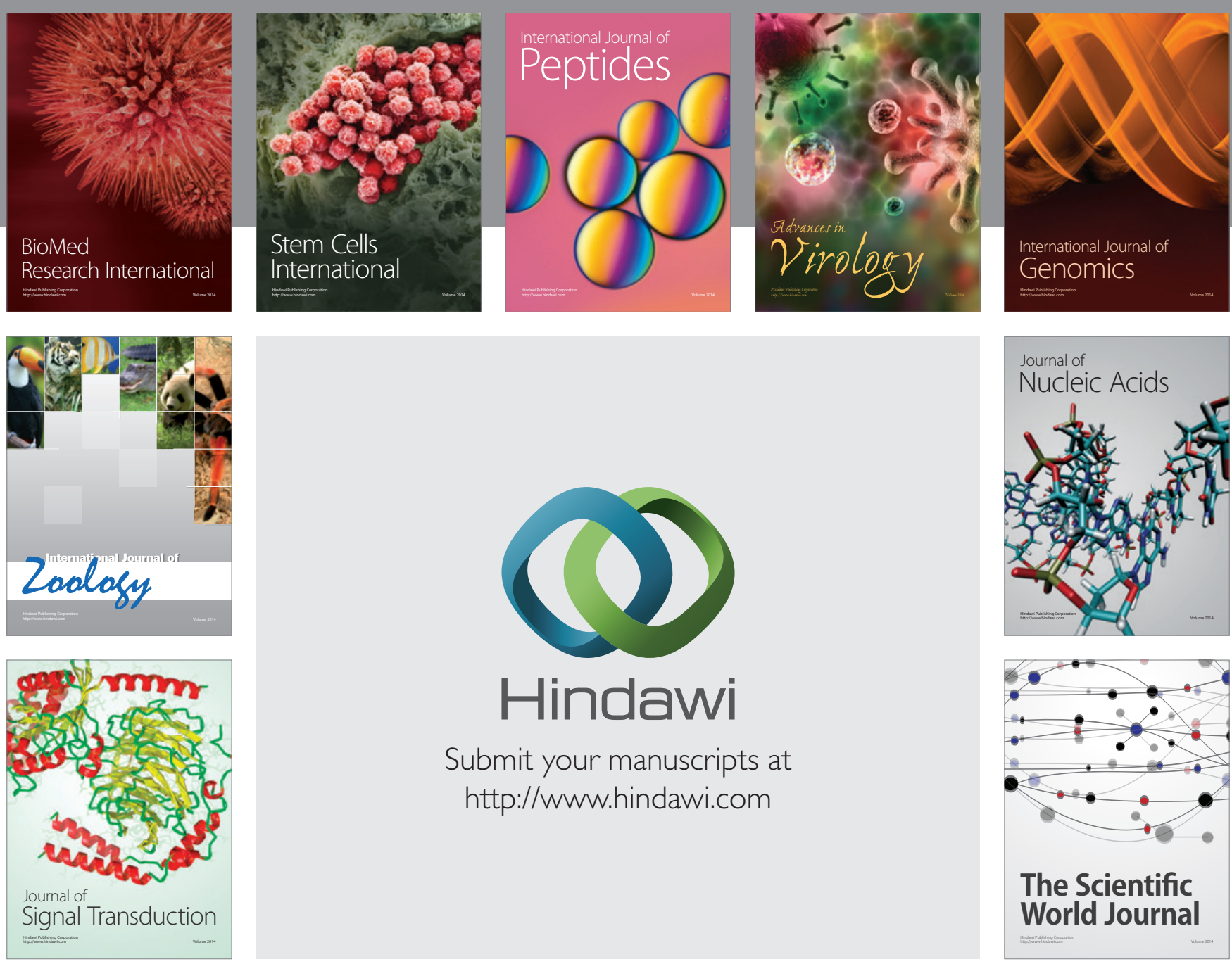

Submit your manuscripts at

http://www.hindawi.com
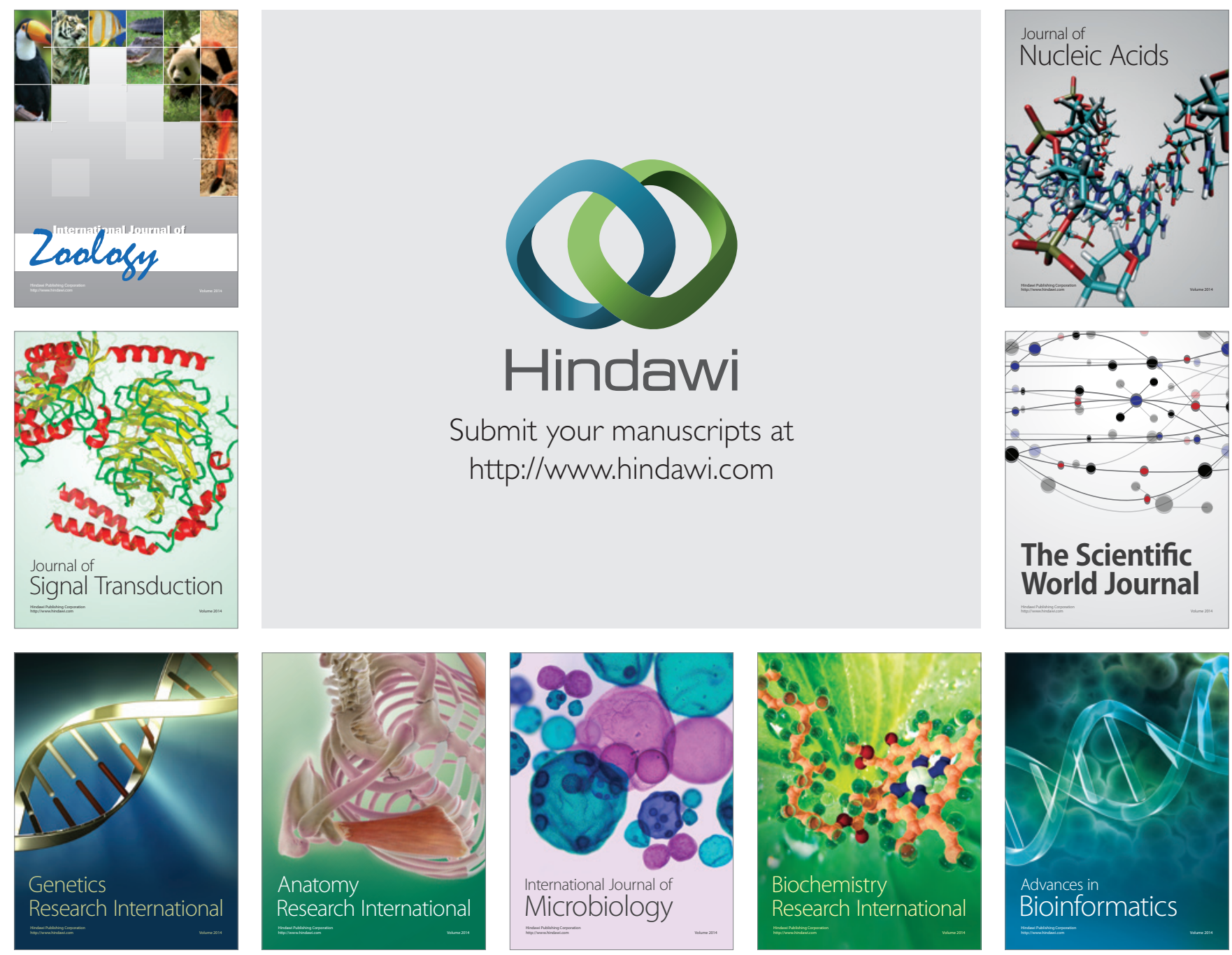

The Scientific World Journal
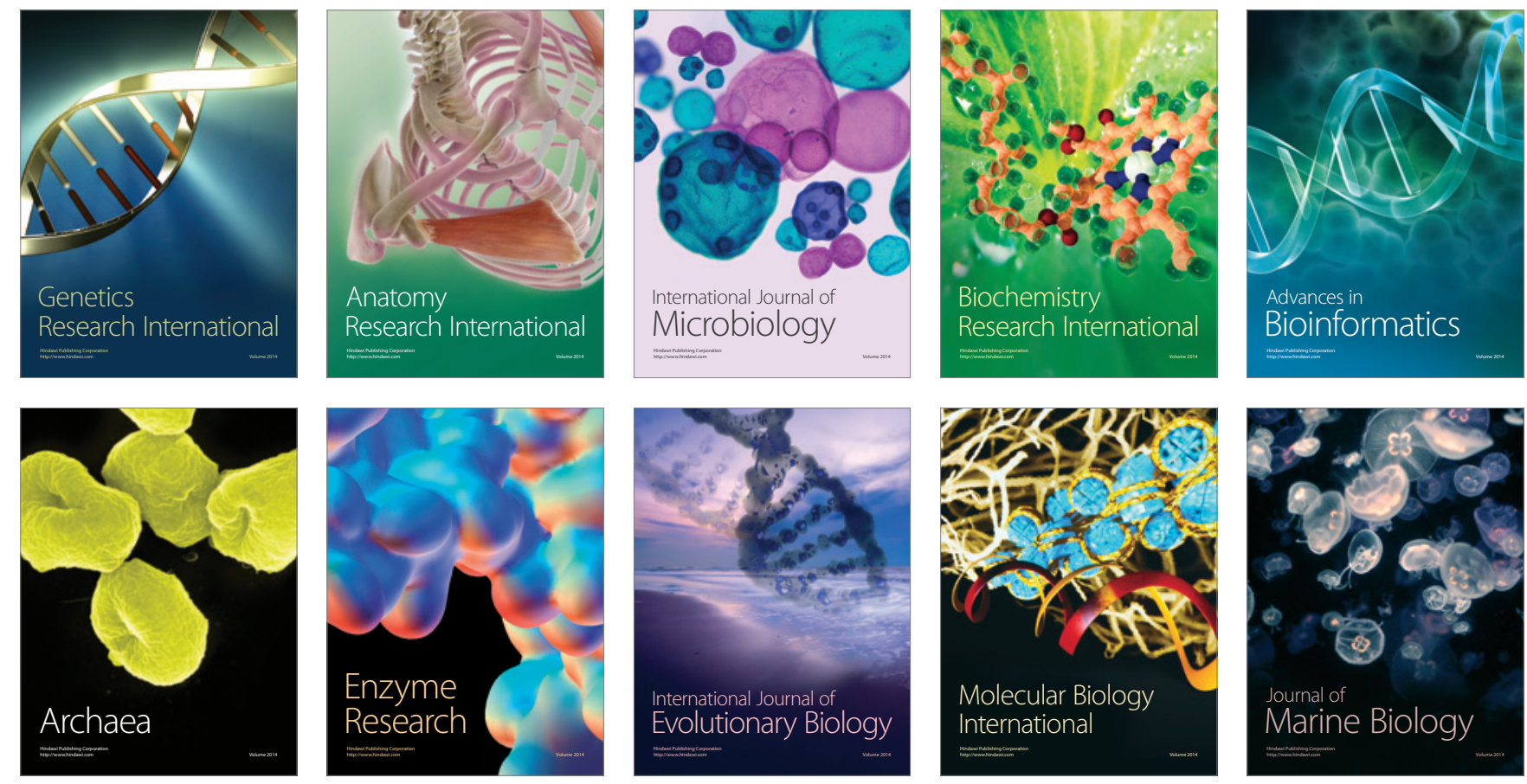